\title{
DOIS PROJETOS DE TRADUÇÃO PARA A REPÚBLICA DOS SONHOS, DE NÉLIDA PIÑON
}

\author{
Lenita Rimoli Esteves ${ }^{1^{\times}}$ \\ ${ }^{1}$ Universidade de São Paulo, Brasil
}

\begin{abstract}
Resumo
Após uma breve apresentação do romance A república dos sonhos, de Nélida Piñon, este trabalho analisa suas traduções para o inglês e o espanhol e, por meio dessa análise, busca elucidar os pressupostos que guiaram o projeto de cada tradução. A investigação é baseada na hipótese de que, antes mesmo de iniciar uma tradução, os tradutores precisam tomar várias decisões quanto à própria concepção do texto a ser produzido. Essas decisões em geral se referem a características do texto de partida que são intimamente ligadas à cultura, à história e à língua do país de origem, e os projetos de tradução buscarão a melhor forma de dar a conhecer ao leitor da tradução essas características. Os elementos paratextuais (GENETTE, 2009), que são parte fundamental de qualquer projeto de tradução, serão analisados juntamente ao texto em si, dando-se especial atenção às capas. Palavras-chave: A república dos sonhos; The republic of dreams; La república de los sueños; Nélida Piñon; tradução literária.
\end{abstract}

\section{TWO TRANSLATION PROJECTS FOR A REPÚBLICA DOS SONHOS, BY NÉLIDA PIÑON}

\begin{abstract}
After a brief presentation of the novel A república dos sonhos, by Nélida Piñon, this paper analyzes its translations into English and Spanish and, through this analysis, aims at shedding some light on what were the presuppositions guiding each translation project. The study is based on the hypothesis that, even before starting a translation, translators must make several decisions concerning the very conception of the text to be produced. These decisions are generally related to characteristics of the source text that are closely linked to the culture, the history and the language of the source country, and each translation project will search for the best way to make these characteristics known to the reader of the translation. The paratextual elements (GENETTE, 2009), which are a fundamental part of any translation project, will be analyzed together with the text itself, with special emphasis on the covers.

Keywords: A república dos sonhos; The republic of dreams; La república de los sueños; Nélida Piñon; Literary translation.
\end{abstract}

\footnotetext{
Possui mestrado em Linguística Aplicada pela Universidade Estadual de Campinas (1992) e doutorado em Linguística pela Universidade Estadual de Campinas (1999). Atualmente é professora doutora da Universidade de São Paulo. Realizou pesquisa de pós-doutorado entre agosto e dezembro de 2008, junto à University of Massachusetts at Amherst. Tem experiência na área de Letras, com ênfase em Tradução, atuando principalmente nos seguintes temas: Tradução, Psicanálise, Tradução e Ética, Tradução Literária e James Joyce. Seu e-mail é lenitaesteves@usp.br. ORCID: https://orcid.org/0000-0003-0525-5048
} 


\section{Introdução}

A edição comemorativa dos trinta anos de publicação de $A$ república dos sonhos, de Nélida Piñon, revela um pouco sobre como a narrativa foi concebida. Anotações feitas em papéis avulsos, listando nomes de personagens, datas e acontecimentos históricos importantes do Brasil, vão dando uma pista de como a autora estruturou o andaime a partir do qual construiu o romance. Páginas datilografadas com diversas rasuras e reescritas indicam o processo de amadurecimento e elaboração da narrativa. Trata-se de uma obra de fôlego. As edições brasileiras têm mais de 700 páginas. Um artigo publicado na revista Istó́ à época do lançamento de $A$ república afirma que, em sua fase de concepção, o livro chegou a ter 5000 páginas (A PAIXÂO, 2015, Anexo).

Sobre um pano de fundo histórico que abrange a história político-social do Brasil desde o início do século XX, a narrativa se inicia com Madruga, aos 13 anos, desembarcando no Brasil, vindo da Galícia, e termina ao final dos anos 1980, quando o mesmo Madruga é um idoso e desencantado imigrante, apesar de ter "conquistado a América", como fora seu sonho de garoto. Contudo, a obra também faz uma incursão no passado quando Venâncio, amigo inseparável de Madruga que o conheceu durante a viagem para o Brasil, escreve uma espécie de diário delirante em que insere personagens da história principal (a saber, ele mesmo, Madruga, sua esposa Eulália e Odete, a empregada/dama de companhia de Eulália) e os mescla a personagens históricos, como o pintor alemão Rugendas, o mestre de reza Tomás Cachaço e outro pintor, esse brasileiro, frei Leandro Joaquim.

Líderes políticos, tanto do século XIX quanto do século XX, também figuram na obra. Começando por D. João VI e terminando com o Presidente Figueiredo, esses personagens reais são mencionados com mais ou menos detalhe, funcionando como pontos por onde passam a linha da História. Getúlio Vargas ganha destaque especial porque, além de ter ficado longo tempo no poder, é alvo da adoração de Odete, a empregada que representa as classes menos favorecidas e pranteia a morte do presidente com a mesma intensidade com que pranteou a do cantor Francisco Alves.

Assim, Nélida Piñon vai tecendo uma narrativa em que entram fios fictícios e reais, e cujo resultado é um todo orgânico, embora a sequência temporal não seja respeitada, e fatos mais antigos convivam com acontecimentos recentes em um mesmo capítulo, até em um mesmo parágrafo, imitando as idas e vindas da memória. O mencionado "pano de fundo histórico" não é apenas um cenário para o que se narra. Os horrores da escravidão, cujas sequelas constatamos até hoje na opressão e na injustiça social sofridas pela comunidade negra no Brasil, são encarnados por Odete, que precisa inventar uma família para se sentir minimamente bem no convívio com a família de Madruga e Eulália. Órfã acolhida em uma instituição de caridade, Odete não tem ancestrais mas os inventa, para diminuir o abismo de desigualdade que a separa da família branca. Ela temia que seu "desprezível nascimento, a orfandade, ferissem a delicadeza 
de Eulália" (PIÑON, 1987, p. 138). Em algumas passagens, todo esse sofrimento é condensado em poucas palavras, como por exemplo quando, ao narrar sua história, Odete diz: "No início, me chamavam de Ana. Aos dez anos a diretora estranhou, onde já se viu uma crioulinha responder pelo nome da mãe de Maria? Aí passaram a me chamar Odete..." (PIÑON, 1987, p. 138).

Mesmo lidando com um período bastante longo e com várias gerações de personagens, e tratando de temas que, sendo de foro íntimo dos personagens, estão entrelaçados com a realidade sócio-política do país, A república dos sonhos é uma história densa e profunda, que mereceu ser acolhida em outros sistemas literários por meio de traduções para o inglês, francês, espanhol e galego, para circular nos EUA e na Grã-Bretanha, além da França, Espanha, Colômbia, Galícia e Portugal.

O objetivo principal deste trabalho é explorar as traduções da obra para o inglês e o espanhol, mas antes se fazem necessários mais alguns apontamentos sobre o romance em português, que serão organizados em tópicos para facilitar a exposição.

\section{A linguagem}

Como todo artista autoral, Nélida Piñon tem dicção própria e diferenciada. Logo nas primeiras páginas, um leitor estreante em suas obras nota uma escrita em certo sentido coloquial, que não segue estritamente a norma culta do português brasileiro. Quando um escritor consagrado desafia regrinhas puristas como a da diferenciação entre "este" e "esse", isso pode ser sinal de que as tais regrinhas não fazem mais tanto sentido no uso atual da língua, mesmo num registro literário. Mas talvez o que mais chame a atenção desse leitor que se inicia na obra de Piñon seja uma estrutura frasal solta, alguns poderiam dizer truncada, combatida por professores de redação. Por exemplo, já no primeiro capítulo da obra se manifesta essa redação com frases que esperaríamos ver encadeadas por conjunções, mas que aparecem separadas por ponto final:

A cadeira de balanço, de uso exclusivo de Madruga, fazia-o sentirse num barco à deriva. Os movimentos pendulares, mais acelerados, tumultuavam-lhe os pensamentos. Forçando-o a refletir sobre a morte, quando ainda preferia explicar a vida. Sobretudo afiar a memória, e deixála para Breta (PIÑON, 1987, p. 9)

Na narrativa, há várias ocorrências de um estilo que se afasta um pouco das normas estritas da gramática da língua culta. Apresentamos alguns exemplos, com o desvio ressaltado em negrito, e com o que seria considerado mais adequado entre colchetes:

Pois nada podia ofendê-lo tanto que [quanto] a sua inabilidade em lidar com o dinheiro" (PIÑON, 1987, p. 11).

Não eram os viventes em geral exóticos, até pelo fato da [de a] vida ultrapassá-los com sua extrema e singular realidade? (PIÑON, 1987, p. 149). 
- Eu lhe [a] trouxe hoje aqui, Breta, para conhecer o que esteve sempre por trás da minha história" (PIÑON, 1987, p. 345) .

-... Prefiro mesmo contar histórias do que [a] vivê-las (PIÑON, 1987, p. 395).

- ...O que pode [podem] significar para eles os pedaços de vidas que nós mesmos decidimos preservar? (PIÑON, 1987, p. 532).

Tobias demonstrava indiferença à evocação dos antepassados. No papel de vassalo permanente da história contemporânea, servia-lhe [serviamlhe] unicamente os acontecimentos em curso, dando as costas ao passado (PIÑON, 1987, p. 564).

Podemos buscar um motivo para esse estilo de Piñon no próprio interior da narrativa. Breta, a neta favorita de Madruga, é quem fica encarregada de continuar a história da família, que passará do registro oral para o escrito. Há várias passagens em que ela oferece suas impressões sobre a língua e o ofício do escritor. $\mathrm{O}$ trecho a seguir vem bem a calhar quando pensamos nesse traço de coloquialidade da obra como um todo:

- É preciso buscar a linguagem certa. Pobre do escritor que se equivoque nesta escolha. Sobretudo há que se escrever na língua principal, que o país está produzindo naquele momento. Se Montaigne tivesse escrito em latim, ninguém o recordaria agora. A mesma sorte não se deu com Francisco de Sanchez, um filósofo inscrito na corrente de Montaigne. Descrente ele dos avanços do seu tempo, apelou para o latim erudito, sem compreender os novos rumos da História. Com isto desprezou os movimentos sísmicos dos povos em formação, todos já reclamando o emprego da língua vulgar (PIÑON, 1987, p. 725).

Outro traço de singularidade na linguagem do romance é uma "invasão" de termos galegos/espanhóis na voz dos três narradores, a saber, um narrador onisciente em terceira pessoa, Madruga e sua neta Breta. Em outras palavras, em vez de esses termos estrangeiros ficarem restritos às falas dos personagens imigrantes, eles também se apresentam nas falas de personagens brasileiros e invadem a linguagem das três vozes narrativas, não se restringindo ao narrador Madruga, que é galego. Em artigo anterior, formulamos a hipótese de um "metanarrador", ou "narrador contrabandista", que informaria as três vozes narrativas (uma galega e duas brasileiras) com termos e expressões que não pertencem estritamente ao português do Brasil, como "arrebato", "de cerca", "algo (se) passar a alguém”.1 Essas expressões são empregadas indiscriminadamente por personagens galegos e brasileiros, bem como pelos três narradores.

Em uma resenha que trata da edição comemorativa de $A$ república dos sonhos, pelos 30 anos desde a primeira publicação, Luís Augusto Fischer aponta essa confluência entre as falas de vários personagens e narradores como um ponto fraco da obra. ${ }^{2} \mathrm{Na}$ nossa opinião, e como procuramos demonstrar no referido trabalho, a invasão da linguagem do "metanarrador" nas vozes de vários 
personagens e também nas dos outros narradores acaba dando uma unidade especial à obra, que remete a um comentário feito por Alberto Mussa em seu prefácio à edição comemorativa:

Foi só depois de A república dos sonhos que o Brasil adquiriu, ou conquistou, sua Galiza. Só depois de A república dos sonhos a Galiza se abrasileirou porque obteve uma expressão em nova língua, a língua literária brasileira. Como se Nélida produzisse, assim, a emersão de um novo continente, de uma espécie de Atlântida, que estivesse a meio entre Europa e América, para criar, ou restabelecer, a ponte (MUSSA, 2015, p. 19).

Assim, o que para alguns leitores pode se configurar como uma falha, para outros pode assumir uma simbologia mais abrangente e mais profunda, dando maior unicidade à obra. O "metanarrador" de Piñon cruza as fronteiras da língua portuguesa assim como Madruga e Venâncio cruzaram a do Brasil, local que escolheram como nova pátria, sem que nela se sentissem totalmente acolhidos. A mistura das expressões e termos estrangeiros à narrativa em português nos faz lembrar, em várias passagens, que para esses dois personagens principais a questão do pertencimento a uma ou outra pátria nunca fica resolvida. Essa sensação fica bem expressa em passagens como esta fala de Venâncio: “- De que me vale a riqueza de ter duas pátrias, se as duas me querem dividir, ambas me fazem sentir que não pertenço a lugar nenhum” (PIÑON, 1987, p. 198-199).

\section{As referências a figuras públicas, lugares, costumes e produtos espe- cificamente brasileiros}

Trata-se de problema que se coloca praticamente em toda tradução. Antigamente, era às vezes um obstáculo intransponível. Como lidar com objetos culturais e símbolos que são específicos da língua/cultura fonte? As opções em geral são: supressão, substituição ou explicação (por meio de uma nota de rodapé, por exemplo).

Eugene Nida, ministro protestante e linguista considerado um dos fundadores dos Estudos da Tradução, discorreu sobre o problema da transposição de termos culturalmente marcados entre línguas muito distantes. Em 1945, ele publicou os resultados de uma análise de várias traduções da Bíblia para diversas línguas aborígenes e discorreu sobre os vários problemas encontrados. Nesse artigo, Nida propõe a divisão dos "problemas de equivalência" entre os seguintes campos: (1) ecologia; (2) cultura material; (3) cultura social; (4) cultura religiosa; (5) cultura linguística (NIDA, 1945, p. 196).

Baseando-se em Nida e trazendo a questão da tradução do que denomina "marcadores culturais", ${ }^{3}$ Francis Aubert revê a distinção de Nida e a reformula, tratando-a em termos de a) "referencialidade intralinguística", que equivale à cultura linguística de Nida; b) referencialidade intertextual; e c) referencialidade extratextual (AUBERT, 2006, p. 29). Para o que nos concerne aqui, os elementos de $A$ república dos sonhos que se referem a figuras públicas, lugares, costumes 
e produtos especificamente brasileiros, a referencialidade extralinguística é a mais relevante. $\mathrm{E}$ os modos de lidar, na tradução, com os elementos típicos de determinada cultura vêm mudando bastante.

Antes do impressionante salto tecnológico que testemunhamos no âmbito das comunicações nas últimas décadas, as traduções eram feitas por um grupo privilegiado de pessoas, que tinham um bom poder aquisitivo, que viajavam frequentemente para o exterior e lá passavam períodos consideráveis. Bons tradutores pertenciam a uma elite que tinha condições de conviver com outras culturas. Durante muitas décadas, era comum que diplomatas e professores universitários de literaturas estrangeiras adotassem a tradução como uma atividade secundária.

Nos dias de hoje, podemos dizer que a atividade de traduzir está mais democratizada e profissionalizada. Temos outras formas de acessar dados das culturas estrangeiras, sem necessariamente precisarmos viajar para os respectivos países. Praticamente todas as respostas e explicações podem ser encontradas na Internet, principalmente pelo Google, nosso oráculo contemporâneo. Além da globalização das informações, o avanço tecnológico nos contemplou com softwares que vêm em auxílio do tradutor, registrando termos e sintagmas já usados para que não tenhamos que repetir uma busca. Mesmo para as traduções de textos literários, essas ferramentas podem ser de grande ajuda no caso de nomes de lugares ou pessoas, e até no caso de termos relacionados a costumes e objetos culturais específicos de uma localidade.

As duas traduções aqui analisadas foram feitas antes do advento dessas facilidades tecnológicas e mostram bem isso, às vezes na inconsistência do tratamento dispensado a um termo, que pode variar ao longo da narrativa, às vezes produzindo equívocos, mesmo no afã de trazer mais informação.

A república dos sonhos, no quadro histórico que compõe do Brasil, traz muitos nomes de figuras públicas que provavelmente são desconhecidas dos leitores-alvo. A decisão de fornecer informações sobre esses personagens faz parte do projeto de tradução concebido para a obra. De qualquer forma, vale apontar que não haveria condições de explicitar para o leitor estrangeiro quem são todas essas personalidades. Getúlio Vargas, como já foi comentado, tem um destaque especial, sendo que o período em que esteve no poder corresponde a uma época de grandes progressos por parte de Madruga, que já tem os filhos maiores, com os quais começa a entrar em conflito. Além de Getúlio, vários outros líderes políticos são citados.

Em relação aos termos referentes a produtos específicos do Brasil, vamos nos limitar a mencionar a cachaça, que seria, na proposta de Aubert, colocada no campo da referencialidade extratextual e que pode ser considerada um dos símbolos culturais do país. As duas opções mais óbvias para a tradução desse termo são substituí-lo por algum termo que se possa considerar equivalente (o que, dependendo da escolha, pode causar protestos) ou mantê-lo em português, explicando-o ou não em uma nota de rodapé. Por exemplo, na tradução de Dona Flor e seus dois maridos para o inglês, feita por Harriet de Onís, o termo "cachaça" 
foi traduzido simplesmente por "rum", o que causou a indignação de alguns. Esse livro apresenta, no final, um glossário que tenta explicar os termos locais. O esforço não foi elogiado por Nadia Kerecuk, fundadora do Brazilian Bilingual Book Club, que classificou o tal glossário de "inútil".

A questão do glossário e de outras tentativas de trazer mais informações para o leitor estrangeiro esbarra na qualidade das informações oferecidas e na própria adequação da tradução. Esse mesmo artigo de Nadia Kerecuk sobre Dona Flor menciona que a tradutora Harriet de Onís nunca havia estudado português e que outros autores não ficaram satisfeitos com seu trabalho, entre eles Gilberto Freyre (KERECUK, 2017, p. 6-7). Voltaremos a esse tópico mais adiante.

Haveria vários outros aspectos a destacar na descrição de $A$ república dos sonhos, mas os já elencados bastam para que possamos partir para a análise das traduções. Antes disso, porém, gostaríamos de relembrar um texto clássico dos Estudos da Tradução, que nos permitirá balizar a comparação entre original e traduções. Trata-se de "Sobre os diferentes métodos de tradução", de Friedrich Schleiermacher, em que ele estabelece duas maneiras pelas quais o tradutor pode "aproximar estas duas pessoas tão separadas, seu escritor e seu leitor": "Ou bem o tradutor deixa o escritor o mais tranquilo possível e faz com que o leitor vá a seu encontro, ou bem deixa o mais tranquilo possível o leitor e faz com que o escritor vá a seu encontro" (SCHLEIERMACHER, 2010, p. 57).

Essa célebre afirmativa, que corre o risco de resvalar para o prosaico sem a devida contextualização, servirá, contudo, para fazermos a distinção primordial entre os dois projetos: o texto em inglês parece ter deixado a autora "o mais tranquila possível", ou, melhor dizendo, a tradutora não se desdobrou para explicar aspectos da cultura brasileira que poderiam causar dificuldade para o leitor. Já a versão espanhola traz várias notas e explicações, que analisaremos a seguir.

\section{The republic of dreams e La república de los sueños}

A tradução inglesa foi realizada por Helen Lane, norte-americana que, em 1980, havia traduzido mais de 60 títulos do francês, espanhol, português e italiano (CHRIST, 1980, p. 6). A obra foi publicada nos Estados Unidos pela Alfred A. Knopf, editora conhecida por publicar obras estrangeiras. ${ }^{5}$ A edição não traz textos explicativos nem notas de rodapé. A única informação adicional vem nas orelhas da sobrecapa, consistindo em um resumo comentado da obra.

Já a tradução para o espanhol foi realizada pelo tradutor, poeta, contista e artista gráfico colombiano Elkin Obregón Sanín. O livro foi lançado na Colômbia em 1991, tendo chegado à Espanha em 1999 por meio da editora Alfaguara (VILLANUEVA, 1999, s.p.). A edição aqui analisada é de 2004, tendo sido publicada pelo Círculo de Lectores, um clube de livros. ${ }^{6}$ Ao que tudo indica, a tradução não passou por atualização nem revisão quando foi transferida de uma editora para outra. Essa hipótese se justifica pelas notas de rodapé que, escritas para a edição de 1991, poderiam ter sido atualizadas. Não parece ser o que ocorreu, como veremos adiante. 
Essa tradução para o espanhol se assemelha à tradução inglesa no que diz respeito a não trazer prefácios ou introduções. O volume também traz um resumo comentado da história na orelha da sobrecapa da frente, sendo que a outra orelha traz dados biográficos de Piñon.

Em relação às características de linguagem do original comentadas acima, observa-se que as duas traduções mantêm as frases "quebradas" ou interrompidas. Reproduzimos a seguir as traduções do trecho citado anteriormente para ilustrar esse ponto:

A cadeira de balanço, de uso exclusivo de Madruga, fazia-o sentirse num barco à deriva. Os movimentos pendulares, mais acelerados, tumultuavam-lhe os pensamentos. Forçando-o a refletir sobre a morte, quando ainda preferia explicar a vida. Sobretudo afiar a memória, e deixála para Breta (PIÑON, 1987, p. 9)

The rocking chair, reserved for Madruga's exclusive use, made him feel as though he were in a drifting boat. The movements back and forth, faster and faster, muddled his thoughts. Forcing him to reflect on death, at a time when he would prefer to explain life. And above all else, to sharpen his memory and leave it to Breta as an inheritance (PIÑON, 1989, p. 5).

La silla mecedora, de uso exclusivo de Madruga, le hacía sentirse en un barco a la deriva. Los movimientos pendulares, más acelerados, ayudaban al tumulto de sus pensamientos. Obligándolo a reflexionar sobre la muerte cuando aún prefería explicar la vida. Y sobre todo a aguzar la memoria, para entregarla como herencia a Breta (PIÑON, 2014, p. 11).

Nota-se que as duas traduções seguem bem de perto a estrutura do texto em português. Além disso, os dois tradutores sentiram a necessidade de acrescentar algo ao trecho "deixá-la para Breta", que no inglês ficou "and leave it to Breta as an inheritance", e no espanhol "para entregarla como herencia a Breta". No mais, a frase quebrada é reproduzida nas duas traduções, e essa é uma tendência geral dos dois textos.

Já com relação aos ligeiros desvios da norma culta do português brasileiro, não se observa nada semelhante em inglês nem em espanhol. Se as traduções tentassem reproduzir esse traço, deveriam encontrar outras formas de manifestálo, segundo as regras de cada língua. Cabe aqui indagar se a tradutora e o tradutor perceberam essa característica, já que para notá-la deveriam ter um conhecimento da língua portuguesa semelhante ao de um falante nativo culto e defensor de um certo purismo. Reproduzimos abaixo as traduções dos trechos citados anteriormente para ilustrar esse leve desvio, com os grifos onde ele "deveria" ocorrer. No caso da tradução para o inglês, a única coisa que se pode notar, às vezes, é a contração do verb to be, que talvez pudesse representar um traço de coloquialismo, mas não há mais que isso. Na tradução para o espanhol, não se nota discrepância alguma. 
Pois nada podia ofendê-lo tanto que [quanto] a sua inabilidade em lidar com o dinheiro (PIÑON, 1987, p. 11).

For nothing could offend Madruga as much as Venâncio's inability to handle money (PIÑON, 1989, p. 7).

Pues nada podía ofender tanto a éste como su incapacidad de lidiar con el dinero (PIÑON, 2014, p. 13)

Não eram os viventes em geral exóticos, até pelo fato da [de a] vida ultrapassá-los com sua extrema e singular realidade? (PIÑON, 1987, p. 149).

Weren't the living in general exotic, even though life far outstripped them with its extreme and singular reality? (PIÑON, 1989, p. 124).

¿No eran exóticos todos los seres vivientes, incluso por el hecho de que la vida los sobrepasaba con su extrema y singular realidad? (PIÑON, 2014, p. 155)

- Eu lhe [a] trouxe hoje aqui, Breta, para conhecer o que esteve sempre por trás da minha história... (PIÑON, 1987, p. 345.

"I brought you here today, Breta, to learn what has always been behind my story..." (PIÑON, 1989, p. 294).

- Te he traído hoy aquí, Breta, para que conozcas lo que hay detrás de mi historia... (PIÑON, 2014, p. 354)

-... Prefiro mesmo contar histórias do que [a] vivê-las (PIÑON, 1987, p. 395).

“...It's just that I prefer recounting adventures to living them." (PIÑON, 1989, p. 338).

- ...La verdad es que prefiero contar aventuras a vivirlas (PIÑON, 2014, p. 402)

- ...O que pode [podem] significar para eles os pedaços de vidas que nós mesmos decidimos preservar? (PIÑON, 1987, p. 532).

"... What can bits and pieces of lives that we ourselves decided to preserve mean to them?" (PIÑON, 1989, p. 460).

-... ¿Qué pueden representar para ellos esos pedazos de vida, cuya guarda, por cierto, no fue idea suya? (PIÑON, 2014, p. 535).

Tobias demonstrava indiferença à evocação dos antepassados. No papel de vassalo permanente da história contemporânea, servia-lhe [serviamlhe] unicamente os acontecimentos em curso, dando as costas ao passado (PIÑON, 1987, p. 564).

Tobias was palpably indifferent to the evocation of his ancestors. In the role of permanent vassal of contemporary history, the only thing of use 
to him were events taking their course, fleeing the past (PIÑON, 1989, p. 486).

Tobías se mostraba indiferente a la memoria de los antepasados. Vasallo de la actualidad, sólo a ella dedicaba su atención. Incluso, en toda actitud política que no engendrase transformaciones inmediatas veía un dato innecesario, casi de carácter arqueológico (PIÑON, 2014, p. 566).

Nos dois últimos excertos, é possível perceber que a tradução para o espanhol se distanciou do original e da tradução para o inglês. Ao passo que o original diz "os pedaços de vidas que nós mesmos decidimos preservar" e o texto em inglês traz algo bem semelhante, "pieces of lives that we ourselves decided to preserve", o texto em espanhol deixa a afirmação menos específica: em vez de dizer que foram os pais que tomaram a iniciativa de preservar as memórias, diz apenas que a iniciativa não foi dos filhos. É claro que o contexto aclara a que pessoas a fala se refere, e portanto essa diferença não chega a ser significativa.

No último trecho o desvio é maior no espanhol. Enquanto o original e o texto em inglês são bastante paralelos, com "servia-lhe [serviam-lhe] unicamente os acontecimentos em curso, dando as costas ao passado" e "the only thing of use to him were events taking their course, fleeing the past", o texto em espanhol "floreia" a ideia, acrescentando a noção de "casi de carácter arqueológico".

Embora não seja esse aspecto que estamos analisando, é difícil não notar a diferença, relacionando esse "floreio" do tradutor para o espanhol com o que Darío Villanueva chamou em sua resenha de "tom quase empolado" de alguns personagens. (VILLANUEVA, 1999). ${ }^{7}$ Embora o que estejamos examinando nesse ponto sejam os desvios em relação à norma culta das línguas, e apesar de não termos pesquisado amplamente materiais sobre a recepção das traduções nas culturas de chegada, a opinião desse resenhista pode sinalizar para a hipótese de que a tradução para o espanhol, além de não ter promovido esses pequenos desvios, talvez tenha optado por um enobrecimento do texto. A escrita de Piñon, nesse romance, não é nem um pouco empolada; ao contrário, aproxima-se de um registro mais cotidiano.

Passemos então agora para o outro problema levantado anteriormente, ou seja, as referências a figuras públicas, lugares, costumes e produtos especificamente brasileiros, que estariam, nos termos de Aubert, no campo da referencialidade extratextual. É sob esse aspecto que as duas traduções mais divergem, o que nos levou a recordar os dois modos de traduzir segundo Schleiermacher. Como já foi sugerido, os dois projetos de tradução tomaram atitudes opostas, sendo que o primeiro deixou para o leitor a tarefa de se aproximar da autora, e o segundo se preocupou em trazê-la ao leitor da tradução. Nem sempre, entretanto, com bons resultados.

Comecemos por um termo muito representativo da cultura gastronômica brasileira, "cachaça", sem perder de vista que em Dona Flor and her two husbands ele foi traduzido simplesmente por "rum", para a indignação de Kerecuk. Passemos a verificar qual foi o tratamento dispensado ao vocábulo em cada projeto de tradução. É importante ressaltar que, sendo um produto tão popular e difundido em nossa cultura, há vários nomes para cachaça em português. Mas vamos nos 
concentrar nesse termo específico, que se refere a um produto brasileiro, no mesmo sentido em que "tequila" é um produto mexicano e "champagne" é um produto francês (LACERDA, 2016, s. p.). ${ }^{8}$ Vamos examinar algumas ocorrências no original e nas traduções. Na primeira vez que "cachaça" ocorre em português, o tradutor espanhol o explica em uma nota, ao mesmo tempo em que escolhe um equivalente em espanhol. $\mathrm{O}$ texto em inglês às vezes empresta o termo do português e outras vezes escolhe outro vocábulo. Esta passagem se relaciona à morte de Getúlio Vargas e à grande comoção nacional gerada pelo suicídio do presidente.

O povo dispersou-se. Alguns na birosca, entre risos, emborcavam a cachaça, a cerveja gelada, esquecidos do conflito. No entanto, em meio à cachaça, o choro, a revolta, a frustração iniciara-se a entronização daquilo que passava a ser a memória de Getúlio Vargas (PIÑON, 1987, p. 324).

The crowd dispersed. Some people in the barrelhouse, between guffaws, drained their glasses of raw rum, their ice-cold beers, the conflict already forgotten. However, amid the rum, the tears, the rebellion, the frustration, there had begun the enthronement of what was about to become the memory of Getúlio Vargas (PIÑON, 1989, p. 277).

El pueblo se dispersó. Algunos, en la tenducha de la plazoleta, tomaban cachaza $^{*}$ y cerveza helada, olvidados ya del conflito.

Sin enbargo, en medio de la cachaza, el llanto, la revuelta y la frustración, comenzaba a fraguarse el mito en que habría de tornarse el recuerdo de Getulio Vargas.

* Cachaça, en portugués. Aguardiente de caña. (N. del T.) (PIÑON, 2014, p. 334-5)

Daí por diante, a tradução para o espanhol mantém o termo "cachaza", mas às vezes escolhe outras designações, como logo veremos. Já o texto em inglês às vezes usa o termo importado do português, e outras vezes escolhe "raw rum", ou "rum", como na tradução da obra de Jorge Amado.

- Até mesmo cachaça. Está na hora de você provar uma branquinha, disse contente (PIÑON, 1987, p. 354).

"Even a cachaça. It's time you had a snort of raw rum", he said happily (PIÑON, 1989, p. 302)

- Inclusive una cachaza. No nos caería mal una copita - decía contento (PIÑON, 2014, p. 364).

O motivo na aparência fora torpe. O levante originando-se da proibição da venda e fabricação de aguardente na cidade e nos engenhos de todo o país.

- Só os negros foram excluídos deste decreto. Os únicos autorizados a fazer uso do vinho da cachaça. E isto porque o álcool destilado era fonte de energia, e recomendado para os escravos.

A proibição reduzia a expansão política da região. E, na prática, ao se obstruir a produção e a venda de vinho de mel, de aguardente e da 
cachaça, decretava-se automaticamente a falência dos engenhos, e do Rio de Janeiro. A reação veio violenta, contra o cumprimento da lei. [...]

- Graças à cachaça, o Rio de Janeiro conseguiu autonomia administrativa no século dezessete. E pôs o povo no governo. In vino veritas (PIÑON, 1987, p. 428).

The motive, to all appearances, had been ignoble. The uprising stemming from the prohibition of the sale and production of cachaça in the city and in sugar mills throughout the country.

"Only blacks were exempted. The only ones allowed sugarcane wine. And this was because alcohol was a source of energy and recommended for slaves".

Prohibition reduced the political expansion of the region. And in practice, curbing the production and sale of mead, cane brandy and rum automatically brought on the financial failure of the sugar mills, and of Rio de Janeiro. A violent reaction set in against observing the law [...]

"Thanks to cachaça, Rio de Janeiro secured administrative autonomy in the seventeenth century. And put the people in charge. In vino veritas." (PIÑON, 1989, p. 376).

El motivo, en apariencia, había sido torpe: un edicto que prohibía la fabricación y venta de aguardiente en la ciudad, y en los ingenios de todo el estado.

- Sólo los negros fueron excluídos del veto. Se les autorizó el consumo de vino y de cachaza. Gracias a que el licor era considerado una óptima fuente de energía, lo cual lo hacía más que recomendable para uso de los esclavos.

La prohibición frenaba la expansión política de la región. Y, en la práctica, al suprimirse el comercio de los aguardentes y vinos de caña, se decretaba automáticamente la quiebra de los ingenios, y de Río de Janeiro. La reacción no se hizo esperar [...]

- Gracias a la cachaza, Río de Janeiro logró ser autónomo en el siglo diecisiete. Y el pueblo probó las mieles del poder. In vino veritas (PIÑON, 2014, p. 434).

Com um rápido gole de cachaça, refrescava ao mesmo tempo as cordas vocais e a vida (PIÑON, 1987, p. 662).

With a quick swallow of cane brandy, he treated his vocal cords and his life to a simultaneous pick-me-up (PIÑON, 1989, p. 574).

Con un trago de cachaza, refrescaba las cuerdas vocales y la vida (PIÑON, 2014, p. 664).

Podemos observar nas ocorrências acima que, embora a palavra tenha sido importada para o inglês e substituída por um cognato em espanhol, isso não foi feito com muita consistência, o termo às vezes sendo substituído por "rum" em inglês e, em outro excerto, sendo usado quando na passagem do original se encontra "aguardente". Em espanhol, parece ter havido um equívoco na tradução de "vinho de cachaça", que aparece como "vino y cachaza". Essa relativa inconsistência na tradução do termo "cachaça" não prejudica a apreciação da obra. Ao mesmo tempo, indica que a tradução foi feita em uma época em que não havia recursos eletrônicos de auxílio ao tradutor. O uso de softwares de memória 
teria facilmente resolvido a questão. Verifica-se também que, assim como ocorreu com a tradução de Dona Flor para o inglês, os textos não passaram por nenhuma revisão ao serem republicados.

Além disso, podemos notar certo "embelezamento" da linguagem no espanhol, reforçando a tendência observada pelo resenhista Villanueva, quando encontramos "Y el pueblo probó las mieles del poder" para "E pôs o povo no governo" em português, sendo que em inglês a escolha do tradutor se aproxima bastante do original, com "And put the people in charge".

O próximo passo de nossa análise será a observação de outras notas de rodapé acrescentadas à tradução para o espanhol, que demonstram a preocupação do tradutor em trazer Nélida Piñon para perto do leitor da língua estrangeira, um cuidado que não se observa com tanta intensidade no texto em inglês. Como poderemos observar, no entanto, nem sempre essa atitude do tradutor para o espanhol esclarece corretamente algumas passagens do texto, embora as notas atestem sua intenção de aclarar ao leitor o sentido dos marcadores culturais de referência extratextual.

\section{O que foi considerado obscuro pelo tradutor para o espanhol}

Esta seção tratará de um aspecto que de certa forma continua a discussão anterior, sendo que o tradutor espanhol, diante de termos que considerou específicos da cultura brasileira (ou marcadores culturais nos termos de Aubert), resolveu explicar ao seu leitor de que se tratava. Colocamos aqui o original, a tradução para o inglês e a tradução para o espanhol para que se possa perceber com mais facilidade a divergência de atitude dos dois tradutores, que tomaram direções opostas que se identificam com as duas possibilidades previstas por Schleiermacher.

Não seria correto afirmar que a tradutora do texto para o inglês descuida totalmente do leitor, obrigando-o a aclarar, por si só, elementos que possam lhe ser desconhecidos. Algumas vezes, ela tenta dar mais informações no próprio corpo do texto, ao passo que o tradutor para o espanhol acrescenta uma nota. Vejamos dois exemplos:

Agora sobretudo inquietos todos com as atividades de Jango na presidência (PIÑON, 1987, p. 129).

All of them especially concerned about Jango Goulart's activities in the office of president (PIÑON, 1989, p. 108).

Ahora, inquietos sobre todo con las actividades de Jango ${ }^{\star}$ en la presidencia.

${ }^{*}$ Nombre con que se suele aludir en Brasil al presidente João Goulart. (N. del T.) (PIÑON, 2014, p. 135).

Venâncio percorria os becos da cidade até o esgotamento. Às vezes entrava no Palácio do Monroe, para assistir às suas sessões (PIÑON, 1987, p. 189). 
Venâncio roamed the back streets of the city till he was exhausted. Sometimes he entered the Palácio do Monroe, to attend the sessions of the Chamber of Deputies (PIÑON, 1989, p. 160).

Venancio recorría los rincones de la ciudad hasta el agotamiento. A veces entraba a las sesiones del Palacio del Monroe.*

* Antiguo edificio del Congreso, hoy desaparecido. (N. del T.) (PIÑON, 2014, p. 197)

Em outras ocasiões, e talvez com mais frequência, a tradutora para o inglês não se preocupa em esclarecer nada ao leitor. Bastará um exemplo para que isso fique explicitado:

- São mentiras forjadas para derrubar Getúlio. Que peso pode ter este Gregório na vida da República? (PIÑON, 1987, p. 314).

"They're lies invented to overthrow Getúlio. What weight can that Gregório fellow have in the life of the Republic?...” (PIÑON, 1989, p. 268).

- Son mentiras forjadas para derribar a Getulio. ¿Qué peso puede tener este tal Gregorio* en la vida de la República?

${ }^{*}$ Gregorio Fortunato, llamado El Ángel Negro, en esa época jefe de la guardia personal de Getulio Vargas. Su presunta vinculación al atentado de la calle Tonelero fue uno de los principales argumentos esgrimidos por la oposición para responsabilizar de esos hechos al propio Presidente ( $N$. del T.) (PIÑON, 2014, p. 324).

Aqui ficam bem distintas as posturas dos dois tradutores quanto ao esclarecimento do leitor. $\mathrm{O}$ tradutor para o espanhol julgou adequado explicar quem foi Gregório Fortunato, ao passo que não esclarece na obra quem foi Getúlio Vargas, provavelmente por julgar que se tratava de personagem bem conhecido, inclusive no exterior.

Por vezes as notas sugerem associações que parecem difíceis de entender, como na passagem abaixo:

Ao lhe passar a isca de peixe, falei de repente. - Se lhe pegam, Breta, nada posso fazer por você (PIÑON, 1987, p. 266).

As I passed her the fish appetizer, I suddenly spoke my mind. "If they nab you Breta, I can't do a thing for you (PIÑON, 1989, p. 226).

Mientras le ofrecía un pasabocas de pescado, dije de súbito:

- Si te prenden, ${ }^{*}$ Breta, nada puedo hacer por ti.

${ }^{\star}$ Hay aqui un posible juego de palavras. Isca de Peixe, para efectos del texto, es un pasabocas de pescado. Pero Isca puede traducirse como carnada. ( $N$. del T.) (PIÑON, 1989, p. 276). 
A cena se desenrola no contexto da ditadura militar. Madruga está tentando convencer Breta a não se envolver em atividades perigosas em reação ao golpe de 1964. O tradutor supôs que em "isca" haveria um duplo sentido significativo nesse momento. De fato, "isca" pode significar, como ele afirma na nota, tanto "aperitivo" como "chamariz para atrair animais", mas supor que Breta estaria nessa ocasião na situação de isca, funcionando como chamariz ou engodo para as autoridades da repressão não faz sentido, já que a própria Breta era seu alvo.

A última nota que analisaremos traz informações imprecisas quanto ao povo gaúcho.

Gaúcho de Alegrete, Silveira fazia brilhante carreira política (PIÑON, 1987, p. 144).

A gaucho from Alegrete, Silveira was forging a brilliant political career (PIÑON, 1989, p. 120).

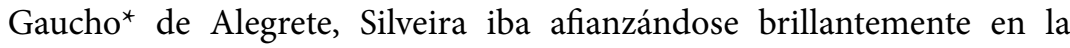
política.

*Nombre que se da en Brasil a los oriundos de los estados del sur (Paraná, Santa Catarina y Rio Grande do Sul. (N. del T.) (PIÑON, 2014, p. 150).

Aqui há dois aspectos interessantes: o fato de o tradutor ter confundido "rio-grandense" com "habitante da região sul do país" e também o de ter usado o termo "gaucho", sem acento, o que faz pensar que ele escolheu a palavra em espanhol, que se refere mais à Argentina e ao Uruguai do que ao Brasil. Se pretendia usar o termo no sentido do português brasileiro, talvez tivesse sido melhor o tradutor empregá-lo com acento e em itálicas, para indicar tratar-se de um termo estrangeiro à língua de chegada.

Esta seção sobre as notas do tradutor nos demonstrou que, apesar da "boa intenção" que as motivam, nem sempre as notas cumprem a função desejada. Podem-se criar equívocos e inexatidões, e é difícil manter uma coerência quanto a qual informação acrescentar. Donde se conclui que, apesar da necessária existência de um projeto de tradução, ela não garante uma coerência perfeita com as decisões tomadas.

Por outro lado, é importante enfatizar mais uma vez que essas traduções foram realizadas antes dos avanços tecnológicos que tanto ajudam os tradutores na atualidade e que têm tornado as notas cada vez menos importantes. Se, por um lado, as traduções não foram revisadas ou atualizadas, por outro lado é mais perdoável a presença dessas inexatidões e incoerências em traduções feitas nos anos 1980 do que nas de hoje em dia.

Passaremos agora para o último ponto a ser analisado, que se liga à parte física dos livros. 


\section{Os livros físicos e as capas}

A parte física dos livros também é importante na percepção que deles tem o leitor. O tamanho das letras, o espaço entre as linhas, o tipo do papel, a qualidade da encadernação, tudo isso influencia o leitor na decisão de comprar o livro e também na sua fruição. O que se pode dizer sobre os três volumes aqui analisados é que a encadernação do original é bem inferior à das traduções americana e espanhola. A edição comemorativa de 30 anos da publicação em português, entretanto, é de qualidade sensivelmente superior em relação à terceira edição que temos em mãos, de 1987. Nas últimas décadas as editoras têm primado mais pela qualidade material dos livros, o que é louvável e muito importante, fato que pode demonstrar um maior respeito para com livros e leitores.

Eu seu livro Paratextos editoriais, Gérard Genette explica que as capas, como as conhecemos hoje, são recentes:

A capa impressa, em papel ou papelão, é um fato bastante recente, que parece remontar ao início do século XIX. Na era clássica, os livros apresentavam-se em encadernação de couro muda, salvo a indicação sumária do título e, às vezes, do nome do autor, que figurava na lombada. [...] Uma vez descobertos os recursos da capa, parece que muito depressa começou-se a explorá-los (GENETTE, 2009, p. 27).

Um fato que chamou nossa atenção durante a análise e as pesquisas na Internet realizadas para a composição deste trabalho foi a questão das capas, principalmente as capas das obras brasileiras traduzidas. Esse assunto merece ser explorado em um trabalho específico, mas agora comentaremos apenas as capas das traduções aqui estudadas em suas várias edições. As edições brasileiras de A república dos sonhos a que tivemos acesso trazem capas sem ilustrações. Nas edições estrangeiras as capas são quase invariavelmente coloridas e chamativas, trazendo imagens relacionadas ao Brasil ou à América Latina. A edição comemorativa traz, em seu fechamento, uma série de capas da obra traduzida para outras línguas e/ou veiculada em outros países. O conjunto de imagens é tão sintomático de uma necessidade de "vender" o Brasil com todos os clichês a ele associados (Rio de Janeiro, carnaval, samba, futebol, mulheres seminuas, etc.), ou vinculando-o a imagens da América Latina.

Essas imagens dizem muito sobre como somos vistos em outros países e sobre o que se espera de nós em termos de exportação cultural. Se vamos ou não continuar respondendo a essa demanda e como faremos isso é questão para outro trabalho.

\section{Conclusão}

Este trabalho propôs uma análise comparativa de duas traduções de $A$ república dos sonhos com base no conceito de projeto de tradução, ou seja, a concepção que se constrói do que uma tradução deverá ser antes que ela seja iniciada. Essas escolhas dão conformação ao texto traduzido e pressupõem uma 
série de expectativas para determinada obra. Não seria necessário dizer que essas expectativas se baseiam em uma projeção feita pelos profissionais envolvidos na produção do livro (e não só pelo tradutor) e pode ser mais ou menos míope.

No cotejo entre as obras, chegou-se à conclusão de que a tradução para o inglês tentou "trazer o leitor até o autor", nos termos da diferenciação de Schleiermacher, ao passo que a tradução para o espanhol foi em sentido contrário e tentou "trazer o autor até o leitor". Todas as notas do tradutor acrescentadas a La república de los sueños dão pistas do que o tradutor e a equipe editorial pensavam sobre os possíveis leitores da obra, de sua familiaridade com o Brasil e de seu desejo em relação a essas informações. Julgou-se que havia a necessidade de explicitar certos termos ou fatos, mas essas informações às vezes causaram mais confusão do que esclarecimento.

Após uma consideração das características linguísticas do texto de Piñon em comparação às traduções para o inglês e o espanhol, chegou-se à conclusão de que certos desvios em relação à norma culta que caracterizam o estilo da autora não foram reproduzidos nas traduções. Por outro lado, as quebras sintáticas do original foram seguidas muito de perto pelas duas traduções.

$\mathrm{Na}$ análise da referencialidade extratextual, verificaram-se estratégias diferentes na tradução para o inglês e o espanhol, o que confirma a visão de que os dos projetos tomaram direções opostas em relação ao tradutor levar o autor ao leitor ou vice-versa.

Uma obra traduzida tem uma coerência interna que é aproximativa e nunca exata. As inconsistências podem ocorrer, como observamos na análise comparativa. Isso chama a atenção para a complexidade da produção de livros e para o número de profissionais envolvidos nesse processo. A luta pela visibilidade do tradutor se torna mais robusta se for evidenciado que a produção de um livro é um projeto coletivo, sendo o tradutor mais um participante; importante, sem dúvida, mas inserido num círculo de interdependência com vários outros profissionais.

Notas

1. Trata-se de comunicação intitulada "O narrador contrabandista: o metanarrador galego de A República dos sonhos e sua recriação nas traduções do romance para o espanhol e o inglês", apresentada no I Congreso Internacional de Literatura Brasileña, realizado em Salamanca, na Espanha, entre 12 e 15 de novembro de 2018.

2. "A alternância dos narradores, que poderia imprimir variedade ao andamento, pouca diferença faz, porque as três vozes são rigorosamente iguais, se exprimem com o mesmo vocabulário, a mesma sintaxe, a mesma obsessão por objetivar, dramatizar, realçar em excesso" (FISCHER, 2015).

3. Segundo Aubert, a noção de marcador cultural "remete a um elemento distintivo, isto é, a algo que diferencia determinada solução expressiva linguisticamente formulada de outra solução tida por parcial ou totalmente equivalente" (AUBERT, 2006, p. 29).

4. "Please ignore the useless glossary (named 'Foreign words and expressions')" (KERECUK, 2017, p.7) 
5. A editora foi fundada por Alfred e Blanche Knopf em 1915. Em 1960 foi adquirida pela Random House, que em 1998 foi comprada pela Bertelsmann e agora faz parte do Knopf Doubleday Publishing Group (ALFRED A. KNOPF).

6. Segundo a descrição do website "Un club del libro en el que disfrutarás de las mejores ofertas para comprar libros, cine, música y mucho más, con descuentos de hasta el 30\%. Y todo esto, sin moverte de casa". (CÍRCULO).

7. "Y no me abandona la sensación de que el trabajo del traductor ha incrementado notablemente el tono casi tribunicio de los parlamentos de ciertos personajes." (VILLANUEVA, 1999, s. p.)

8. Segundo o dicionário Houaiss, a origem do termo é bastante controversa, não sendo possível determiná-la com exatidão. Existe, no entanto, um registro histórico de 1635, no sentido de "aguardente de cana" (HOUAISS).

\section{Referências:}

ALFRED A. KNOPF. In: Wikipedia, the free encyclopedia. Disponível em: https:// en.wikipedia.org/w/index.php?title=Alfred_A._Knopf\&oldid=861893437. Acesso 24 out. 2018.

AUBERT, F. Indagações acerca dos marcadores culturais na tradução. Revista de Estudos Orientais, n. 5, p. 23-36, 2006.

A PAIXÃO do verbo. IstoÉ, 5 set. 1984. In: PIÑON, N. A república dos sonhos. Edição comemorativa 30 anos. [Anexo: A História de A república dos sonhos]. Rio de Janeiro: Record, 2015.

CACHAÇA. In: HOUAISS, A. Grande Dicionário Houaiss Eletrônico. Disponível em: https://houaiss.uol.com.br/pub/apps/www/v3-3/html/index.php\#3. Acesso em 26 out. 2018.

CHRIST, R. The translator's voice: an interview with Helen R. Lane. Translation Review, 5, n. 1, 1980. 6-18.

CÍRCULO. Círculo de Lectores - Espacio online de cultura. Disponível em: https:// www.circulo.es/. Acesso em 25 out. 2018.

FISCHER, L. A. Pretensa saga da imigração galega se perde em adjetivações. Folha de São Paulo, São Paulo, 13 set. 2015. Disponível em: https://wwwl.folha.uol.com. br/ilustrissima/2015/09/1680463-pretensa-saga-da-imigracao-galega-se-perdeem-adjetivacoes.shtml Acesso em 27 out. 2018.

GENETTE, G. Paratextos editoriais. Tradução de Álvaro Faleiros. Cotia, SP: Ateliê Editorial, 2009.

KERECUK, N. Jorge Amado. Dona Flor e seu dois Maridos. Brazilian Bilingual Book Club. Disponível em: http://londres.itamaraty.gov.br/en-us/book_club.xml. Acesso em 24 out. 2018.

LACERDA, M. Após 15 anos de espera, cachaça vira produto exclusivo do Brasil. Canal Rural UOL. UOL: 31 out. 2016. Disponível em: https://canalrural.uol.com. br/programas/apos-anos-espera-cachaca-vira-produto-exclusivo-brasil-64479/. Acesso em 30 out. 2018.

MUSSA, A. A emersão de Atlântica. In: PIÑON, N. A república dos sonhos. Edição comemorativa 30 anos. Rio de Janeiro: Record, 2015.

NIDA, E. Linguistics and Ethnology in Translation - Problems. Word, v. 1, n. 2, p. 194-208, 1945.

PIÑON, A. A república dos sonhos. 3 ed. Rio de Janeiro: Francisco Alves, 1987. 
PIÑON, A. A república dos sonhos. Edição comemorativa 30 anos. Rio de Janeiro: Record, 2015.

PIÑON, A. The republic of dreams. Tradução de Helen Lane. New York: Alfred Knopf, 1989.

PIÑON, A. La república de los sueños. Tradução de Elkin Obregón Sanín. Barcelona: Círculo de Lectores, 2014.

SCHLEIERMACHER, F. Sobre os diferentes métodos de traduzir. In: HEIDERMANN, W. Classicos da teoria da tradução. Tradução de Celso R. Braida. 2. ed. Florianópolis: UFSC/Núcleo de Pesquisas em Literatura e Tradução, v. 1, 2010.

VILLANUEVA, D. La república de los sueños - Nélida Piñon. El Cultural, Madrid, 15 jul. 1999. Disponível em https://www.elcultural.com/revista/letras/La-republicade-los-suenos/14532. Acesso em 26 out. 2018.

Recebido: 09/11/2018

Aceito: 02/04/2019 